\title{
The Japan Environment and Children's Study (JECS): A Preliminary Report on Selected Characteristics of Approximately 10000 Pregnant Women Recruited During the First Year of the Study
}

Takehiro Michikawa1 ${ }^{\text {, Hiroshi Nitta }}{ }^{1}$, Shoji F. Nakayama' ${ }^{1}$ Masaji Ono ${ }^{1}$, Junzo Yonemoto', Kenji Tamura ${ }^{1}$, Eiko Suda ${ }^{1}$, Hiroyasu Ito ${ }^{1}$, Ayano Takeuchi ${ }^{1}$, and Toshihiro Kawamoto ${ }^{1,2}$, for the Japan Environment and Children's Study Group*

${ }^{1}$ National Center for the Japan Environment and Children's Study, National Institute for Environmental Studies, Tsukuba, Ibaraki, Japan

${ }^{2}$ Department of Environmental Health, University of Occupational and Environmental Health, Kitakyushu, Fukuoka, Japan

Received October 1, 2014; accepted December 14, 2014; released online April 25, 2015

Copyright (C) 2015 Takehiro Michikawa et al. This is an open access article distributed under the terms of Creative Commons Attribution License, which permits unrestricted use, distribution, and reproduction in any medium, provided the original author and source are credited.

\begin{abstract}
Background: The Japan Environment and Children's Study (JECS) is an ongoing nationwide birth cohort study launched in January 2011. In this progress report, we present data collected in the first year to summarize selected maternal and infant characteristics.

Methods: In the 15 Regional Centers located throughout Japan, the expectant mothers were recruited in early pregnancy at obstetric facilities and/or at local government offices issuing pregnancy journals. Self-administered questionnaires were distributed to the women during their first trimester and then again during the second or third trimester to obtain information on demographic factors, physical and mental health, lifestyle, occupation, environmental exposure, dwelling conditions, and socioeconomic status. Information was obtained from medical records in the first trimester and after delivery on medical history, including gravidity and related complications, parity, maternal anthropometry, and infant physical examinations.

Results: We collected data on a total of 9819 expectant mothers (mean age $=31.0$ years) who gave birth during 2011. There were 9635 live births. The selected infant characteristics (singleton births, gestational age at birth, sex, birth weight) in the JECS population were similar to those in national survey data on the Japanese general population. Conclusions: Our final birth data will eventually be used to evaluate the national representativeness of the JECS population. We hope the JECS will provide valuable information on the impact of the environment in which our children live on their health and development.
\end{abstract}

Key words: birth cohort; pregnant women; children; environmental chemicals; Japan

\section{INTRODUCTION}

The Japan Environment and Children's Study (JECS) is an ongoing nationwide birth cohort study. ${ }^{1}$ Its primary objective is to investigate environmental factors, such as exposure to chemicals and airborne pollutants, that could affect children's health and development during the fetal stage and early childhood, in order to help policymakers formulate measures to safeguard the environment for future generations.

The plan was to recruit approximately 100000 pregnant women and their partners over a period of three years, to collect biological samples (blood, urine, hair, breast milk, and umbilical cord blood), and to collect data on their children until they reach 13 years of age. In January 2011, we started recruiting women in study areas nationwide, from Hokkaido in the north to Okinawa in the south. The study areas were selected with the intention of making the results of JECS generalizable. So, to check whether recruitment was going according to plan, we decided to summarize the data we collected so far on selected maternal and infant characteristics. To this end, we used data on approximately 10000 women who gave birth in 2011 (the first year of recruitment). 


\section{MATERIALS AND METHODS}

\section{Study participants}

The JECS protocol has been published elsewhere. ${ }^{1}$ Fifteen Regional Centers (Hokkaido, Miyagi, Fukushima, Chiba, Kanagawa, Koshin, Toyama, Aichi, Kyoto, Osaka, Hyogo, Tottori, Kochi, Fukuoka, and south Kyushu/Okinawa) were selected for their wide geographical distribution, and each was made responsible for recruiting pregnant women who lived in administratively defined districts (city, town, or village) within the relevant study area (eTable 1). The women were recruited in early pregnancy at obstetric facilities and/or at local government offices issuing pregnancy journals (Mother-Child Health Handbooks). Recruitment started in January 2011 and continued for three years, until March 2014.

The present study is based on the data set of jecs-ag-ai20131008, which was released in October 2013. The study population was 9838 women who gave birth on or before December 31, 2011. Of these, we excluded participants with missing data on maternal age and gestational age at delivery, leaving us with a total of 9819 mothers, including 94 mothers with multiple registrations. The target recruitment rate is $>50 \%$ of qualified women in the Residential Registry of each study area, and the final rate will be reported when all birth data are confirmed.

\section{Questionnaires and medical record transcription}

The research coordinators distributed self-administered questionnaires at prenatal examinations or by mail to the women during their first trimester (first questionnaire) and again during their second/third trimester (second questionnaire). The completed questionnaires were then returned either by hand at subsequent prenatal visits or by mail. Incomplete answers were supplemented as much as possible through face-to-face or telephone interviews. Table 1 shows the questions used in the two questionnaires to obtain information on demographic factors, medical and obstetric history, physical and mental health, lifestyle, occupation (based on the Japan Standard Occupational Classification, 2009²), environmental exposure, dwelling conditions, and socioeconomic status. These questionnaires included the SF-8 as an indicator of healthrelated quality of life, ${ }^{3}$ the $\mathrm{K} 6$ as an indicator of psychological distress, ${ }^{4-7}$ the short version of the International Physical Activity Questionnaire as an indicator of physical activity, 8,9 the Autism Spectrum Quotient-10 as an indicator of autistic traits, ${ }^{10,11}$ and the food frequency questionnaire used in the Japan Public Health Center-based prospective Study for the Next Generation (JPHC-NEXT). Information was obtained from maternal and infant medical records on medical history, including gravidity and related complications, parity, maternal anthropometry, and infant physical examinations (Table 1). Transcripts of medical records were made twice by physicians, midwives/nurses, or research coordinators, once during each woman's first trimester and again after delivery.
Data collected via the questionnaires and medical transcripts were scanned, converted to electronic data with an optical character recognition device, and then stored in a data management system.

\section{Ethical issues}

The JECS protocol was reviewed and approved by the Ministry of the Environment's Institutional Review Board on Epidemiological Studies and by the Ethics Committees of all participating institutions. Written informed consent was obtained from all participating women.

\section{Statistical analysis}

For the present study, we obtained information about maternal age at delivery, marital status, educational background, household income, smoking habits, passive smoking, alcohol consumption, and history of obstetrical/gynecological diseases from the questionnaires; height and weight before pregnancy, parity, and infertility treatment from both questionnaire and medical record; delivery outcomes (live birth or not, singleton or multiple birth, gestational age at birth, sex, type of delivery, and birth weight) from medical records.

Since both the first and second questionnaires included questions about smoking and alcohol consumption, we used data from the first questionnaire, with supplementary data added from the second questionnaire. We divided smoking status into three categories: never smoked, ex-smokers who quit before pregnancy, smokers during early pregnancy (ie, those who responded "quit after pregnancy was confirmed" or "still smoking"). Alcohol consumption status was divided into three categories in the first questionnaire (never, used to drink, or still drinking), and into four categories in the second questionnaire (never, quit drinking before pregnancy was confirmed, quit drinking after pregnancy was confirmed, or still drinking). From the two sets of responses, we made three groups: never drank, ex-drinkers who quit before pregnancy (those whose cessation after pregnancy was confirmed were not classed as ex-drinkers), or drinkers during early pregnancy. The medical record data on maternal height and weight before pregnancy, parity, and infertility treatment were used when available, with the information collected via questionnaire used only as a fallback measure. Body mass index (BMI) before pregnancy was calculated as weight $(\mathrm{kg}) /$ height squared $\left(\mathrm{m}^{2}\right)$.

The selected characteristics were summarized according to maternal age group $(<25,25-29,30-34$, or $\geq 35$ years $)$ and Regional Center. All analyses were performed with Stata 11 (StataCorp LP, College Station, TX, USA).

\section{RESULTS}

Of the 9819 women, $10.7 \%$ were 24 years old or younger, $28.1 \%$ were 25 to 29 years old, $35.2 \%$ were 30 to 34 years old, and $26.0 \%$ were aged 35 years or older; the mean age 
Table 1. Summary of information collected by questionnaires and medical record transcription in the Japan Environment and Children's Study (JECS)

\begin{tabular}{|c|c|}
\hline & Example of individual item \\
\hline \multicolumn{2}{|c|}{ Maternal questionnaire at the first trimester (the first questionnaire) } \\
\hline Demographic factors & date of birth, age, marital status, family structure \\
\hline \multicolumn{2}{|l|}{ Medical and obstetric history } \\
\hline Physical and mental health & $\begin{array}{l}\text { height and weight before pregnancy, health-related quality of life as measured with the SF- } 8,^{3} \\
\text { psychological distress using the } \mathrm{K}^{4-7}\end{array}$ \\
\hline Lifestyle & $\begin{array}{l}\text { smoking habits (including partner's status), passive smoking, alcohol consumption, dietary habits } \\
\text { before pregnancy using the Food Frequency Questionnaire, physical activity using the short } \\
\text { version of the International Physical Activity Questionnaire }{ }^{8,9}\end{array}$ \\
\hline \multicolumn{2}{|r|}{ ( } \\
\hline \multicolumn{2}{|c|}{ Environmental exposure at home and in workplace } \\
\hline \multicolumn{2}{|c|}{ Maternal questionnaire in the second/third trimester (the second questionnaire) } \\
\hline Demographic factors & date of birth, age \\
\hline Physical and mental health & $\begin{array}{l}\text { health-related quality of life as measured with the SF- } 8,{ }^{3} \text { psychological distress using the } \mathrm{K} 6,{ }^{4-7} \\
\text { autistic traits as measured with the Autism Spectrum Quotient-10, }{ }^{10,11} \text { life events }\end{array}$ \\
\hline Lifestyle & $\begin{array}{l}\text { smoking habits (including partner's status), passive smoking, alcohol consumption, dietary habits } \\
\text { during pregnancy using the Food Frequency Questionnaire, dietary supplement intake during } \\
\text { pregnancy, physical activity using the short version of the International Physical Activity } \\
\text { Questionnaire, }{ }^{8,9} \text { sleeping }\end{array}$ \\
\hline Dwelling conditions & $\begin{array}{l}\text { condition of one's home, use of air conditioning system, presence of visible mold, pets, frequency } \\
\text { of vacuuming, use of chemical substances such as insecticide and repellent }\end{array}$ \\
\hline \multicolumn{2}{|r|}{ ( } \\
\hline \multicolumn{2}{|c|}{ Environmental exposure at home and in workplace } \\
\hline Socioeconomic status & educational background (including partner's status), household income, social capital \\
\hline \multicolumn{2}{|c|}{ Medical record transcription at the first trimester } \\
\hline Demographic factors & date of birth, age \\
\hline Anthropometry & height and weight \\
\hline Medical history of present pregnancy & expected date of confinement, infertility treatment, fetal number \\
\hline Medical history of past pregnancies & \\
\hline \multirow{2}{*}{\multicolumn{2}{|c|}{$\begin{array}{l}\text { Medical record transcription at birth } \\
\text { Maternal }\end{array}$}} \\
\hline & \\
\hline Demographic factors & date of birth, age \\
\hline Medical history & medical and pregnancy complications, infection such as hepatitis virus, medication \\
\hline \multicolumn{2}{|r|}{ ( } \\
\hline Birth record & $\begin{array}{l}\text { date of birth, gestational age, number of live births, type of delivery, fetal presentation, sex, apgar } \\
\text { score, anthropometry, neonatal complications }\end{array}$ \\
\hline Physical examinations & congenital anomalies \\
\hline
\end{tabular}

(standard deviation [SD]) was 31.0 (5.0) years. The first questionnaire was returned by 9563 of the women (97.4\%), and the second questionnaire was returned by 9369 (95.4\%). As shown in Table 2, the majority of the women were married (95.8\%), well-educated ( $63.2 \%$ with $\geq 13$ years of education), and had an appropriate BMI before pregnancy of 18.5 to $24.9 \mathrm{~kg} / \mathrm{m}^{2}(72.8 \%)$. Smokers during early pregnancy accounted for $19.3 \%$ of the participants, and $43.8 \%$ drank alcohol during early pregnancy. The most common pregnancy-related abnormality was pregnancy-induced hypertension (3.6\% among parous women). The proportions of nulliparae and primiparae did not differ substantially (40.9\% vs 38.2\%). Missing information on household income was more common $(10.6 \%)$ than that for other variables.

The selected maternal characteristics according to age groups are shown in Table 2. The younger age groups tended to have higher proportions of smokers during early pregnancy, daily passive smokers, underweight before pregnancy (BMI $<18.5 \mathrm{~kg} / \mathrm{m}^{2}$ ), nulliparae, and participants without infertility treatment. There were no substantial differences among age groups in regard to alcohol consumption. The maternal characteristics according to Regional Center are summarized in eTable 2.

From 9819 deliveries in 2011, a total of 9635 live births and 26 stillbirths (fetal deaths that occurred at $\geq 22$ weeks of gestation) were observed. Of 9635 live births, the proportion of singleton births was $98.2 \%$, the mean gestational age (SD) at birth was 39.0 (1.8) weeks, the proportion of term births was $92.9 \%$, and $51.0 \%$ were male (Table 3 ). Approximately $80 \%$ of the births were by vaginal delivery, with the proportion declining in proportion to age. With regard to singleton births, the mean birth weight (SD) was 3002 (433) g. The distribution of low birth weight (birth weight $<2500 \mathrm{~g}$ ) did not differ substantially across the age groups. The 
Table 2. Selected maternal characteristics in the Japan Environment and Children's Study (JECS) as of 2011

\begin{tabular}{|c|c|c|c|c|c|c|}
\hline \multirow{3}{*}{ Variables } & \multirow{3}{*}{$n^{\mathrm{a}}$} & & \multicolumn{4}{|c|}{ Age at delivery, years } \\
\hline & & Total & $<25$ & $25-29$ & $30-34$ & $\geq 35$ \\
\hline & & $(\%)$ & $(\%)$ & $(\%)$ & $(\%)$ & $(\%)$ \\
\hline Number of mothers & 9819 & 100 & 1049 & 2762 & 3456 & 2552 \\
\hline \multicolumn{7}{|l|}{ Age at delivery, years } \\
\hline Total, mean (SD) & 9819 & $31.0(5.0)$ & & & & \\
\hline$<25$ & & 10.7 & & & & \\
\hline $25-29$ & & 28.1 & & & & \\
\hline $30-34$ & & 35.2 & & & & \\
\hline$\geq 35$ & & 26.0 & & & & \\
\hline Marital status & 9521 & & & & & \\
\hline Married & & 95.8 & 84.5 & 95.2 & 98.1 & 97.7 \\
\hline Unmarried & & 3.3 & 14.3 & 3.7 & 1.3 & 1.1 \\
\hline Divorced/widowed & & 1.0 & 1.2 & 1.2 & 0.6 & 1.1 \\
\hline Educational background, years & 9326 & & & & & \\
\hline$<10$ & & 5.2 & 20.4 & 5.2 & 2.5 & 2.6 \\
\hline $10-12$ & & 31.7 & 54.0 & 34.8 & 25.2 & 28.2 \\
\hline $13-16$ & & 61.8 & 25.4 & 59.2 & 70.5 & 67.4 \\
\hline$\geq 17$ & & 1.4 & 0.2 & 0.9 & 1.9 & 1.7 \\
\hline Household income, million Japanese Yen & 8780 & & & & & \\
\hline$<2$ & & 6.1 & 18.2 & 7.1 & 3.7 & 3.9 \\
\hline 2 to $<4$ & & 35.2 & 51.8 & 42.7 & 32.4 & 24.7 \\
\hline 4 to $<6$ & & 33.0 & 20.7 & 30.8 & 36.2 & 35.5 \\
\hline 6 to $<8$ & & 15.1 & 4.9 & 12.1 & 16.6 & 20.2 \\
\hline 8 to $<10$ & & 6.4 & 1.8 & 4.3 & 7.3 & 9.0 \\
\hline$\geq 10$ & & 4.2 & 2.6 & 2.9 & 3.9 & 6.7 \\
\hline Smoking habits & 9599 & & & & & \\
\hline Never smoked & & 56.5 & 47.4 & 54.3 & 58.9 & 59.2 \\
\hline Ex-smokers who quit before pregnancy & & 24.2 & 17.8 & 22.8 & 25.7 & 26.4 \\
\hline Smokers during early pregnancy & & 19.3 & 34.8 & 22.9 & 15.5 & 14.4 \\
\hline Passive smoking & 9520 & & & & & \\
\hline Rarely & & 47.3 & 24.3 & 41.3 & 53.4 & 54.8 \\
\hline Daily & & 19.9 & 37.3 & 22.0 & 16.2 & 15.9 \\
\hline Alcohol consumption & 9609 & & & & & \\
\hline Never drank & & 35.2 & 36.1 & 36.8 & 35.7 & 32.2 \\
\hline Ex-drinkers who quit before pregnancy & & 21.0 & 21.1 & 19.9 & 21.2 & 22.0 \\
\hline Drinkers during early pregnancy & & 43.8 & 42.8 & 43.3 & 43.1 & 45.8 \\
\hline Body mass index before pregnancy, $\mathrm{kg} / \mathrm{m}^{2}$ & 9768 & & & & & \\
\hline$<18.5$ & & 16.7 & 20.3 & 19.0 & 16.9 & 12.2 \\
\hline 18.5-24.9 & & 72.8 & 70.5 & 71.9 & 71.9 & 75.9 \\
\hline$\geq 25.0$ & & 10.6 & 9.2 & 9.2 & 11.2 & 11.8 \\
\hline History of obstetrical/gynecological diseases & 9563 & & & & & \\
\hline Dysmenorrhea & & 11.0 & 10.7 & 11.5 & 11.9 & 9.6 \\
\hline Endometriosis & & 3.6 & 1.6 & 2.6 & 3.8 & 5.3 \\
\hline Myoma uteri & & 6.2 & 0.4 & 2.2 & 6.2 & 12.6 \\
\hline Adenomyosis uteri & & 0.2 & 0.0 & 0.2 & 0.2 & 0.4 \\
\hline Malformation of uterus & & 0.3 & 0.1 & 0.3 & 0.4 & 0.3 \\
\hline Ovarian tumor/cyst & & 3.4 & 1.7 & 2.7 & 3.6 & 4.7 \\
\hline Polycystic ovary syndrome & & 1.6 & 1.1 & 1.6 & 1.6 & 1.6 \\
\hline Urogenital malformation & & 0.03 & 0.0 & 0.0 & 0.09 & 0.0 \\
\hline Pregnancy-induced hypertension ${ }^{b}$ & & 3.6 & 3.8 & 2.5 & 3.7 & 4.2 \\
\hline Gestational diabetes mellitus $^{b}$ & & 0.8 & 0.6 & 0.5 & 0.8 & 1.2 \\
\hline Placenta abruption ${ }^{b}$ & & 0.5 & 0.0 & 0.2 & 0.6 & 0.6 \\
\hline Ectopic pregnancy ${ }^{b}$ & & 0.9 & 1.1 & 0.6 & 0.9 & 1.2 \\
\hline Placenta previa ${ }^{b}$ & & 0.7 & 0.0 & 0.4 & 0.5 & 1.4 \\
\hline Hydatidiform mole & & 0.6 & 0.6 & 0.7 & 0.8 & 0.5 \\
\hline Parity & 9658 & & & & & \\
\hline 0 & & 40.9 & 62.4 & 49.7 & 35.7 & 29.8 \\
\hline 1 & & 38.2 & 30.3 & 36.5 & 41.9 & 38.4 \\
\hline$\geq 2$ & & 20.8 & 7.4 & 13.8 & 22.4 & 31.9 \\
\hline Infertility treatment & 9792 & & & & & \\
\hline No & & 94.4 & 99.7 & 97.1 & 94.6 & 89.3 \\
\hline
\end{tabular}

$\mathrm{SD}$, standard deviation.

${ }^{\text {aNumber }}$ of mothers without missing value.

${ }^{\mathrm{b}}$ Parous women only $(n=5581)$. 
Table 3. Selected infant characteristics in the Japan Environment and Children's Study (JECS) as of 2011

\begin{tabular}{|c|c|c|c|c|c|c|}
\hline \multirow{3}{*}{ Variables } & \multirow{3}{*}{$n^{\mathrm{a}}$} & \multirow[b]{2}{*}{ Total } & \multicolumn{4}{|c|}{ Maternal age at delivery, years } \\
\hline & & & $<25$ & $25-29$ & $30-34$ & $\geq 35$ \\
\hline & & $(\%)$ & $(\%)$ & $(\%)$ & $(\%)$ & $(\%)$ \\
\hline Number of live births & 9635 & 100 & 1021 & 2730 & 3404 & 2480 \\
\hline Singleton births & & 98.2 & 98.6 & 98.0 & 98.1 & 98.3 \\
\hline \multicolumn{7}{|l|}{ Gestational age at birth, weeks } \\
\hline Total, mean (SD) & 9635 & $39.0(1.8)$ & $39.2(1.7)$ & $39.1(1.8)$ & $39.1(1.7)$ & $38.9(1.9)$ \\
\hline Preterm births $(<37)$ & & 6.9 & 6.5 & 7.4 & 5.6 & 8.2 \\
\hline Term births (37-41) & & 92.9 & 93.4 & 92.4 & 94.1 & 91.7 \\
\hline Postterm births ( $\geq 42)$ & & 0.2 & 0.1 & 0.2 & 0.3 & 0.2 \\
\hline Sex & 9635 & & & & & \\
\hline Male & & 51.0 & 52.3 & 51.7 & 50.1 & 51.1 \\
\hline Female & & 48.8 & 47.2 & 48.0 & 49.7 & 48.8 \\
\hline Missing $^{b}$ & & 0.2 & 0.5 & 0.3 & 0.2 & 0.1 \\
\hline Type of delivery & 9604 & & & & & \\
\hline Vaginal & & 80.3 & 86.8 & 84.0 & 79.8 & 74.2 \\
\hline Cesarean & & 19.7 & 13.2 & 16.0 & 20.2 & 25.8 \\
\hline \multicolumn{7}{|l|}{ Birth weight, g } \\
\hline Total, mean (SD) & 9607 & $2987(447)$ & $2981(425)$ & $2979(441)$ & $2997(441)$ & $2985(471)$ \\
\hline Singleton births & 9430 & & & & & \\
\hline Total, mean (SD) & & $3002(433)$ & $2992(413)$ & $2997(424)$ & $3012(427)$ & $2997(459)$ \\
\hline Male, mean (SD) & & $3046(431)$ & $3050(421)$ & $3041(410)$ & $3052(437)$ & 3044 (449) \\
\hline Female, mean (SD) & & $2956(430)$ & $2929(396)$ & $2952(433)$ & $2973(412)$ & $2948(464)$ \\
\hline Low birth weight $(<2500 \mathrm{~g})$ & & 9.1 & 9.8 & 8.5 & 9.1 & 9.4 \\
\hline
\end{tabular}

$\mathrm{SD}$, standard deviation.

aNumber of infants without missing value.

bIncluding newborns with ambiguous genitalia.

distributions of infant characteristics according to Regional Center are shown in eTable 3.

\section{DISCUSSION}

This is a preliminary report on selected maternal and infant characteristics of the approximately 10000 pregnant women who gave birth during the first year of recruitment (2011) for the JECS.

The JECS study areas encompass the whole of Japan from north to south. We wanted to ensure the study population was representative of the general population, so we compared selected characteristics of the JECS population with those obtained via a national survey (Table 4). ${ }^{12-14}$ In the Vital Statistics survey, ${ }^{12}$ the proportion of nulliparae was determined on the basis of birth order data, so the comparison of Vital Statistics with our results of parity should be done with caution. However, we think the proportion of nulliparae was probably lower in the JECS than in the general population because caution on the part of women in their first pregnancy may have made them hesitate to participate in the present study. There were no essential differences in the distribution of maternal age at delivery between the JECS participants and the general population. The proportions of JECS women aged 20-29 years and those aged $30-39$ years were $37.8 \%$ and $57.1 \%$, respectively; the corresponding figures for Vital Statistics 2011 were $38.5 \%$ and $56.6 \% .^{12}$ Fetal death rate at $\geq 22$ weeks' gestation of the JECS
Table 4. Selected maternal and infant characteristics of the Japan Environment and Children's Study (JECS) and Japanese national surveys

\begin{tabular}{|c|c|c|c|}
\hline & \multirow{2}{*}{$\frac{\text { JECS }}{(\%)}$} & \multicolumn{2}{|r|}{ National survey } \\
\hline & & $(\%)$ & \\
\hline \multicolumn{4}{|l|}{ Maternal characteristics } \\
\hline Age at delivery, years & & & Vital Statistics, $2011^{12}$ \\
\hline $20-29$ & 37.8 & 38.5 & \\
\hline $30-39$ & 57.1 & 56.6 & \\
\hline \multicolumn{4}{|l|}{ Parity } \\
\hline 0 & 40.9 & a & \\
\hline \multicolumn{4}{|l|}{ Infant characteristics } \\
\hline Live births & & & Birth Statistics, $2010^{13}$ \\
\hline Singleton births & 98.2 & 98.0 & \\
\hline Gestational age at birth, weeks & & & Birth Statistics, $2010^{13}$ \\
\hline Term births $(37-41)^{\mathrm{b}}$ & 93.9 & 94.9 & \\
\hline $\mathrm{Sex}^{\mathrm{c}}$ & & & Vital Statistics, $2011^{12}$ \\
\hline Male & 51.1 & 51.2 & \\
\hline Female & 48.9 & 48.8 & \\
\hline Type of delivery & & & Surveys of Medical \\
\hline Cesarean & 19.7 & 19.2 & Institutions, $2011^{14}$ \\
\hline Birth weight ${ }^{b}$ & & & Birth Statistics, $2010^{13}$ \\
\hline Total, mean kg & 3.00 & 3.02 & \\
\hline Low birth weight $(<2500 \mathrm{~g})$ & 9.1 & 8.3 & \\
\hline
\end{tabular}

an Vital Statistics, ${ }^{12}$ birth order has been reported. The proportion of first child among the number of the total births was $47.1 \%$ in 2011 .

bSingleton births only.

${ }^{\mathrm{C} E x c l u d i n g ~ m i s s i n g ~ d a t a . ~}$

population (2.7 per 1000 live births and fetal deaths at $\geq 22$ weeks) did not substantially differ from that of the general population (3.3 per 1000 live births and fetal deaths at $\geq 22$ weeks for Vital Statistics 20112). The proportions of 
singleton births, term births, cesarean births, and low birth weight were also similar between the two sets of data. ${ }^{13,14}$ In addition, the infant male:female ratios were comparable (1.04 for the JECS and 1.05 for Vital Statistics 2011 ${ }^{12}$ ). As of 2011 (the first year of recruitment), the JECS cohort can be regarded as representative of the Japanese general population. The final birth data will eventually be used to evaluate the national representativeness of the JECS population.

Smoking and alcohol consumption are major lifestyle factors strongly suspected of contributing to adverse birth outcomes. ${ }^{15}$ We are separately researching the effects of such maternal lifestyle factors on children's health and development, although JECS puts primary emphasis on involuntary exposure to environmental factors. We compared the lifestyle characteristics of our study population with corresponding data on the general population, but there is actually little nationwide information about smoking and alcohol consumption among Japanese pregnant women. In a 2006 survey at the medical institutions specified by the Japan Association of Obstetricians and Gynecologists for a survey of infectious disease and statistics throughout Japan, ${ }^{16,17}$ approximately 19000 expectant mothers at various stages of pregnancy were asked about their smoking and drinking habits before and after pregnancy. It is difficult to compare the results of this survey with our data with respect to smoking/drinking status during early pregnancy, but the distributions of smokers and drinkers by age groups tended to be similar in the two studies. A prospective cohort study of pregnant women and their children carried out in Koshu City, Project Koshu, ${ }^{18}$ demonstrated similar results: the proportion of smokers during early pregnancy was $21.5 \%$ (current smokers $[6.6 \%]+$ those who quit during early pregnancy $[14.9 \%])$; our finding was $19.3 \%$.

JECS recruitment of participants finished at the end of March 2014 after the registration of approximately 100000 women. After the last participants have given birth in the end of 2014, we will be able to establish the largest birth cohort ever assessed in Japan, which will also be one of the largest globally. The results regarding factors associated with the pregnancy and birth outcomes are forthcoming. The participating children will be followed until they reach 13 years of age, and we expect that the JECS will provide valuable information on the impact of the environments in which our children live on their health and development.

\section{ONLINE ONLY MATERIALS}

eTable 1. Study areas of each Regional Center in the Japan Environment and Children's Study (JECS) as of the start of recruitment (January 2011).

eTable 2. Selected maternal characteristics according to Regional Centers in the Japan Environment and Children's Study (JECS) as of 2011.
eTable 3. Selected infant characteristics according to Regional Centers in the Japan Environment and Children's Study (JECS) as of 2011.

Abstract in Japanese.

\section{ACKNOWLEDGEMENTS}

We would like to express our gratitude to all of the JECS study participants. We wish to express our sincere appreciation to the collaborating hospitals and clinics. We also thank the JECS staff members for their efforts in supporting our study. Finally, we gratefully acknowledge Dr. Hiroshi Satoh (Food Safely Commission, Cabinet Office, Tokyo, Japan) who planned the JECS and was a former principal investigator.

This study was supported by a grant for Japan Environment and Children's Study from the Ministry of the Environment, Japan. The findings and conclusions of this article are solely the responsibility of the authors and do not represent the official views of the above government.

Conflicts of interest: None declared.

\section{APPENDIX}

Members of the Japan Environment and Children's Study (JECS) as of 2014 (principal investigator, Toshihiro Kawamoto): Hirohisa Saito (Medical Support Center for JECS, National Center for Child Health and Development, Tokyo, Japan), Reiko Kishi (Hokkaido Regional Center for JECS, Hokkaido University, Sapporo, Japan), Nobuo Yaegashi (Miyagi Regional Center for JECS, Tohoku University, Sendai, Japan), Koichi Hashimoto, Seiji Yasumura (Fukushima Regional Center for JECS, Fukushima Medical University, Fukushima, Japan), Chisato Mori (Chiba Regional Center for JECS, Chiba University, Chiba, Japan), Fumiki Hirahara (Kanagawa Regional Center for JECS, Yokohama City University, Yokohama, Japan), Zentaro Yamagata (Koshin Regional Center for JECS, University of Yamanashi, Chuo, Japan), Hidekuni Inadera (Toyama Regional Center for JECS, University of Toyama, Toyama, Japan), Michihiro Kamijima (Aichi Regional Center for JECS, Nagoya City University, Nagoya, Japan), Ikuo Konishi (Kyoto Regional Center for JECS, Kyoto University, Kyoto, Japan), Hiroyasu Iso (Osaka Regional Center for JECS, Osaka University, Suita, Japan), Masayuki Shima (Hyogo Regional Center for JECS, Hyogo College of Medicine, Nishinomiya, Japan), Munetsugu Fukumoto (Tottori Regional Center for JECS, Tottori University, Yonago, Japan), Narufumi Suganuma (Kochi Regional Center for JECS, Kochi University, Nankoku, Japan), Toshiro Hara (Fukuoka Regional Center for JECS, Kyushu University, Fukuoka, Japan), and Takahiko Katoh (South Kyushu/Okinawa Regional Center for JECS, Kumamoto University, Kumamoto, Japan). 


\section{REFERENCES}

1. Kawamoto T, Nitta H, Murata K, Toda E, Tsukamoto N, Hasegawa $\mathrm{M}$, et al. Rationale and study design of the Japan environment and children's study (JECS). BMC Public Health. $2014 ; 14: 25$.

2. Japan Standard Occupational Classification [homepage on the Internet]. Ministry of Internal Affairs and Communications, Japan; c2009 [cited 2014 Jun 17]. Available from: http://www. stat.go.jp/english/index/seido/shokgyou/index-co.htm19.

3. Fukuhara S, Suzukamo Y. Manual of the SF-8 Japanese Version. Kyoto: Institute for Health Outcome and Process Evaluation Research; 2004 (in Japanese).

4. Furukawa TA, Kawakami N, Saitoh M, Ono Y, Nakane Y, Nakamura $Y$, et al. The performance of the Japanese version of the K6 and K10 in the World Mental Health Survey Japan. Int J Methods Psychiatr Res. 2008;17:152-8.

5. Furukawa TA, Kessler RC, Slade T, Andrews G. The performance of the $\mathrm{K} 6$ and $\mathrm{K} 10$ screening scales for psychological distress in the Australian National Survey of Mental Health and Well-Being. Psychol Med. 2003;33:357-62.

6. Kessler RC, Andrews G, Colpe LJ, Hiripi E, Mroczek DK, Normand SL, et al. Short screening scales to monitor population prevalences and trends in non-specific psychological distress. Psychol Med. 2002;32:959-76.

7. Kessler RC, Barker PR, Colpe LJ, Epstein JF, Gfroerer JC, Hiripi E, et al. Screening for serious mental illness in the general population. Arch Gen Psychiatry. 2003;60:184-9.

8. Craig CL, Marshall AL, Sjöström M, Bauman AE, Booth ML, Ainsworth BE, et al. International physical activity questionnaire: 12-country reliability and validity. Med Sci Sports Exerc. 2003;35:1381-95.

9. Murase N, Katsumura T, Ueda C, Inoue S, Shimomitsu T. International standardization of physical activity level: reliability and validity study of the Japanese version of the International Physical Activity Questionnaire (IPAQ). J Health Welfare
Statistics (Kosei no Shihyo). 2003;49:1-9 (in Japanese).

10. Baron-Cohen S, Wheelwright S, Skinner R, Martin J, Clubley E. The autism-spectrum quotient (AQ): evidence from Asperger syndrome/high-functioning autism, males and females, scientists and mathematicians. J Autism Dev Disord. 2001;31:5-17.

11. Kurita H, Koyama T, Osada H. Autism-Spectrum QuotientJapanese version and its short forms for screening normally intelligent persons with pervasive developmental disorders. Psychiatry Clin Neurosci. 2005;59:490-6.

12. Vital Statistics [homepage on the Internet]. Ministry of Health, Labour and Welfare, Japan; c2011 [cited 2014 Jun 17]. Available from: http://www.mhlw.go.jp/toukei/list/81-1.html (in Japanese).

13. Birth Statistics [homepage on the Internet]. Ministry of Health, Labour and Welfare, Japan; c2010 [cited 2014 Jun 17]. Available from: http://www.mhlw.go.jp/toukei/saikin/hw/jinkou/tokusyu/ syussyo06/ (in Japanese).

14. Surveys of Medical Institutions [homepage on the Internet]. Ministry of Health, Labour and Welfare, Japan; c2011 [cited 2014 Jun 17]. Available from: http://www.mhlw.go.jp/toukei/list/ 79-1.html (in Japanese).

15. Andersen AM, Olsen J. The Danish National Birth Cohort: selected scientific contributions within perinatal epidemiology and future perspectives. Scand J Public Health. 2011;39 (7 Suppl):115-20.

16. Ohida T, Sone T, Takemura S, Ozaki Y, Kaneita Y, Tamaki T, et al. Smoking status among Japanese pregnant women. Nihon Koshu Eisei Zasshi. 2007;54:115-21 (in Japanese with English abstract).

17. Tamaki T, Kaneita Y, Ohida T, Harano S, Yokoyama E, Osaki $\mathrm{Y}$, et al. Alcohol consumption behavior of pregnant women in Japan. Prev Med. 2008;47:544-9.

18. Suzuki K, Sato M, Zheng W, Shinohara R, Yokomichi H, Yamagata Z. Effect of maternal smoking cessation before and during early pregnancy on fetal and childhood growth. J Epidemiol. 2014;24:60-6. 